\title{
Efficacy of Different Fungicides against Mango Anthracnose in Senegalese Soudanian Agroclimate
}

\author{
Papa Madiallacke Diedhiou1, Yaya Diallo1, Rokhaya Faye ${ }^{2 *}$, Abdou Aziz Mbengue1, \\ Abdou Sene ${ }^{1}$ \\ ${ }^{1}$ Département Productions Végétales et Agronomie, UFR des Sciences Agronomiques d’Aquaculture et des \\ Technologies Alimentaires, Université Gaston Berger, Saint-Louis, Sénégal \\ ${ }^{2}$ Département de Biologie végétale, Université Cheikh Anta DIOP de Dakar, Dakar, Sénégal \\ Email: bilpaco@yahoo.de
}

Received 13 May 2014; revised 10 June 2014; accepted 25 June 2014

Copyright (C) 2014 by authors and Scientific Research Publishing Inc.

This work is licensed under the Creative Commons Attribution International License (CC BY). http://creativecommons.org/licenses/by/4.0/

(c) (i) Open Access

\begin{abstract}
Anthracnose is the one of the most devastating diseases of mango produced in the southern part of Senegal. The field trials against post harvest rot due to anthracnose took place in three orchards over two production seasons, in 2009 and 2010 . Three systemic fungicides (thiophanate methyl, azoxystrobin and myclobutanyl) and one contact fungicide (mancozeb) were tested for their efficacy. The first treatments in 2009 took place in the rainy season, while $20 \%$ of mangoes on trees exhibited anthracnose lesions. At ripening stage, $\mathbf{1 0 0 \%}$ of fruits from non treated control mango trees were affected by anthracnose and got rotten, while between $73.2 \%$ and $80 \%$ of mangoes ripened free of disease when treated with thiophanate methyl. With the treatment with azoxystrobin, between $46.6 \%$ and $60 \%$ of fruits were not infected. Treatment with myclobutanyl was less effective. This level of effectiveness was clearly improved in 2010 by preventive spraying, days ahead of onset of the rainy season, before the appearance of anthracnose symptoms on fruits. The level of effectiveness was higher respectively for thiophanate methyl (between $96 \%$ and $100 \%$ of fruits not infected) and azoxystrobin (between $84 \%$ and $96 \%$ of fruits not infected).
\end{abstract}

\section{Keywords}

Anthracnose, Fungicides, Mango, Soudanian Agroclimate, Senegal

\section{Introduction}

In Senegal, fruit production has increased from 95,075 tons in 1986 to over 150,000 tons in 2003 whereby

\footnotetext{
${ }^{*}$ Corresponding author.
}

How to cite this paper: Diedhiou, P.M., Diallo, Y., Faye, R., Mbengue, A.A. and Sene, A. (2014) Efficacy of Different Fungicides against Mango Anthracnose in Senegalese Soudanian Agroclimate. American Journal of Plant Sciences, 5, $2224-2229$. 
mangoes represent $60 \%$ of this production [1]. In the particular case of the natural region of Casamance, in the southern part of the country, fruit production was considered for a long time an activity of marginal importance in the farmers' agenda. In fact, different tree crop species were always planted in the backyards and around the settlements for the needs of local consumption. An effort to promote commercial fruit orchards by the government included the introduction of exotic species and improved varieties since the year 1860. All improved mango and to a lesser extend citrus varieties from Casamance, like those from the Niayes area in the north, were targeted for export to the European market.

The income generated through fruit export is a major incentive for producers. As a consequence, new orchards are set up resulting in an increasing activity and land surface dedicated to mango production. Mango business is a strong driver of socio-economic development by providing labor but it also attracts other players in the value chain like fruit processers and suppliers.

In the natural region of Casamance, economic activities around mango business have grown significantly and become more profitable for late maturating mango varieties. Those mangoes are however exposed to intensive rainfall from June to September (rainy season) with high temperatures and moisture levels suitable to anthracnose. For the early maturating mango varieties, anthracnose is not an issue but market price is low. The shift towards the late maturating mango varieties is driven by market opportunities in big cities and for export during that period. In these late years, the economic activities around mango business tend to slow down drastically or even stop by onset of the rainy season because of post harvest rot due to anthracnose.

Anthracnose, the most serious disease of mango worldwide, occurs in all production regions that have high rainfall or high moisture level [2]. This disease is caused by, Colletotrichum gloeosporoides, a fungal pathogen in the class of ascomycetes which teleomorph, Glomerella cingulata, is observed rarely on mango.

Anthracnose due to Colletotrichum gloeosporioides Penz. infests all parts of the tree but has a most severe impact on fruits after harvest and causes massive losses. Controlling mango anthracnose in the agroclimate of the Casamance requires taking into account both the intensity of the rainfall activity during flowering and fruit setting of mango trees, and the big size of the mango trees.

To date, fungicides are the most reliable strategy to achieve effective control of anthracnose and safeguard production in humid regions [2]. In Senegal, as commercial orchards were set up in recent years, the need to control disease and anthracnose in particular arises with the imperative for competitiveness in markets.

The present study was carried out to select effective fungicides against anthracnose and identify optimal treatment periods in the context of the specific agro-climate of the region of Casamance.

\section{Material and Methods}

\subsection{Study Site}

The trials were carried out around the village of Djibelor, located at $5 \mathrm{~km}$ west of Ziguinchor, in the south of Senegal. This region has boundaries to Gambia in the north and Guinea Bissau in the south whereas the coast of the Atlantic Ocean represents the western border. It covers $7301 \mathrm{~km}^{2}$, representing $3.74 \%$ of Senegalese territory and harbors the Casamance River [3]. It is the most rainfall rich part of the country with between 700 and 1500 mm over 70 to 80 days. The temperatures vary between $18^{\circ} \mathrm{C}$ in January and $38^{\circ} \mathrm{C}$ in April [3].

\subsection{Biologic Material}

The biological material is made of mango Mangifera indica L (cv Keitt) and Colletotrichum gloeosporioides Penz, the agent of mango anthracnose occurring naturally in the study site. The tests were carried out in 3 mango orchards with trees of more than 15 years of age and a size ranging from between 8 and $20 \mathrm{~m}$ in height. The orchards are located in Djibelor, southwest of the city of Ziguinchor. The trees were not planted in a regular manner resulting in no distinctive rows nor determined distance between trees.

\subsection{Fungicide Tests}

Three systemic fungicides and a contact fungicide were tested in the field to assess their efficacy in the control of field infection and postharvest rot of mango due to anthracnose. Their choice was based on the performance provided by the manufacturers and the literature. The tests were performed in two production seasons in 2009 in 2 orchards and 2010 in 3 orchards.

In 2009, only systemic fungicides were used. Each fungicide was tested on five mango trees. Each tree was 
chosen so as to be surrounded by untreated trees that can serve as a reservoir for recontamination. Mango trees were treated by spraying the fungicide at the dose recommended by the manufacturer on half the foliage. The treated area was marked with a cloth of a color specific to the fungicide. The first application was carried out on 15/07/09 and the second on 29/07/09.

In the second season (2010), the trials involved five mango trees for each fungicide. Unlike in the first session, the mango trees were fully cover sprayed and at an earlier fruiting stage. For each fungicide, a specific color of cloth was chosen for identification. The first application took place on 03/06/10 and the second on 26/06/10.

In each orchard, mango from trees at least planted 20 meters away from the treated area served as untreated control. The characteristics of fungicides used are summarized in Table 1.

\subsection{Fruit Sampling}

Green mature mangoes were sampled at harvest stage, identified by the producers. In the first year, with treatment consisting with covering half of the mango foliage with the fungicide spray, both treated and untreated mangoes from the same tree were sampled. Sampling consisted with picking fruits in a random manner in the treated tree area and the untreated one. Untreated mango trees, used as control, were also sampled. In the second year, five (5) mangoes were sampled randomly on each tree or treated tree part. After sampling fruits were labelled and put in clean bags, placed in cardboards for the transportation to the laboratory.

\subsection{Fruit Incubation}

In the laboratory, the fruits are kept in a clean and airy room temperature (about $26^{\circ} \mathrm{C}-29^{\circ} \mathrm{C}$ ). The number of infested fruit was evaluated daily and the rotting agent was identified.

\subsection{Assessing for the Incidence of Anthracnose}

The assessment for the incidence of anthracnose on fruits was performed as described in the literature [4]. The fruits were washed one by one under the tap, and placed in expedition boxes in a way to prevent contact between them and avoid contaminations. They were let to ripen at the room temperature $\left(27^{\circ} \mathrm{C}-30^{\circ} \mathrm{C}\right)$. The boxes were examined every day for rotting mangoes. Fruits showing rotting symptoms were sorted out for the identification of the causal agent. The symptoms observed were first described and classified. The isolation and identification of the causal agents was performed in case of doubt. The mangoes were first soaked in a $1 \% \mathrm{NaOCl}$ solution for 15 minutes and two crossed incisions in the form of $\mathrm{V}$ are made at the front of progression of the rotting process with a sterile scalpel. A piece of flesh beneath the peal is taken and put in a Petri dish containing Potato Dextrose Agar amended with $100 \mathrm{ppm}$ of chloramphenicole and incubated at $30^{\circ} \mathrm{C}$ in the dark. One to two days later, the mycelium growing out of the mango flesh is transferred into new Petri dishes to obtain pure culture of the fungi.

The data were submitted to an analysis of variance (ANOVA) using the SigmaStat ${ }^{\circledR}$ software with a confidence interval of 95\%. Mean values was separated through Tukey’s tests pairwise comparisons.

\section{Results}

\subsection{Influence of Partial Treatment of Tree Foliage on Incidence of Mango Anthracnose}

Test in Orchard 1 and 2 in 2009

Preharvest treatment with thiophanate methyl kept $80 \%$ of mangoes from foliage covered by the fungicide free

Table 1. Characteristics of fungicides tested.

\begin{tabular}{ccccc}
\hline Active ingredient & Common name & Chemical type & Distrubution in plant & Application dose \\
\hline Azoxystrobin & Ortiva & Strobulirin & Systemic & $250 \mathrm{~g} / \mathrm{l}$ \\
Myclobutanyl & Systane & Triazole & Systemic & $240 \mathrm{~g} / \mathrm{l}$ \\
Thiophanate methyl & Pelt 44 & Benzimidazole & Systemic & $450 \mathrm{~g} / \mathrm{l}$ \\
Mancozeb & Mancozeb 80 W.P & Dithiocarbamate & Contact & $800 \mathrm{~g} / \mathrm{kg}$ \\
\hline
\end{tabular}


of disease. In the same tree, mangoes from foliage parts not covered by the fungicide exhibited $46.6 \%$ of healthy fruits (Table 2). Treatment with azoxystrobin gave respectively for mangoes from the treated and untreated foliage portion $44.4 \%$ and $13.2 \%$ disease free ripe fruits. Treatment with myclobutanyl was the least effective, with only $26.6 \%$ and $6.6 \%$ of uninfected mangoes from the treated and untreated tree portion respectively. From the non treated control trees, no ripe disease free fruit was recorded.

The analysis of variance showed a significative difference between treatments $(\mathrm{p}<0.05)$.

In orchard 2 all fruits from untreated trees were rotten because of anthracnose after 10 days of incubation. Treatment with thiophanate methyl allowed $73.2 \%$ of fruits from sprayed foliage and $46.6 \%$ from unsprayed foliage portion to ripen free of anthracnose. Treatment with azoxystrobin gave intermediate results with $60 \%$ and $33.2 \%$ of mangoes not infested while treatment with myclobutanyl only $40 \%$ and $20 \%$ of mangoes from the treated and untreated tree parts respectively ripened disease free.

\subsection{Influence of Treatment of Entire Foliage on the Incidence of Anthracnose}

In 2010, 8\% of mangoes from untreated control trees were infested in orchard 1 (Table 3). Mancozeb was used to replace myclobutanyl since it is widely available and showed some effectiveness in the northern part of the country [4]. Myclobutanyl was not present in the Senegalese market for regulation. With treatment with mancozeb, $44 \%$ of fruits ripened disease free. Treatment with thiophanate methyl allowed no mango rotting due to anthracnose ( $100 \%$ of mangoes disease free at ripe stage). When trees were treated with azoxystrobin, $96 \%$ of mangoes ripened disease free. The differences between these two treatments were not significative.

In orchard 2, treatment with thiophanate methyl provided $100 \%$ fruit protection with all mangoes, disease free at ripe stage. Treatment with azoxystrobin gave the second best result with $92 \%$ of mangoes free of anthracnose while treatment with mancozeb allowed protecting $84 \%$ of mangoes. Mangoes from the control treatment showed $92 \%$ incidence of anthracnose.

In orchard 3, treatments with thiophanate methyl and azoxystrobin gave the best results with $96 \%$ and $84 \%$ of mangoes free of infection. Treatment with mancozeb preserved $64 \%$ of mangoes while in the non treated control, only $4 \%$ of the fruit remained uninfested.

Table 2. Effect of pre-harvest treatments on incidence of mango anthracnose in 2009. (Numbers followed by different letters are significantly different, Tukey test, $\mathrm{n}=20, \mathrm{p} \leq 0.05$ ). In a column, means followed by a common letter are not significantly different at the $5 \%$ level.

\begin{tabular}{|c|c|c|c|c|}
\hline \multirow{2}{*}{ Treatment } & \multicolumn{2}{|l|}{ Orchard 1} & \multicolumn{2}{|c|}{ Orchard 2} \\
\hline & Treated foliage portion & Untreated foliage portion & Treated foliage portion & Untreated foliage portion \\
\hline Untreated & $0^{\text {c }}$ & & $0^{c}$ & \\
\hline Myclobutanyl & $26.6^{\mathrm{bc}}$ & $6.6^{\mathrm{c}}$ & $20^{\mathrm{b}}$ & $40^{\mathrm{b}}$ \\
\hline Azoxystrobin & $46.6^{\mathrm{b}}$ & $13.2^{\mathrm{c}}$ & $33.2^{\mathrm{b}}$ & $60^{\mathrm{ab}}$ \\
\hline Thiophanate methyl & $80^{\mathrm{a}}$ & $44.4^{\mathrm{b}}$ & $46.6^{\mathrm{ab}}$ & $73.2^{\mathrm{a}}$ \\
\hline
\end{tabular}

Table 3. Effect of pre-harvest treatments on incidence of mango anthracnose in 2010. (In each column, numbers followed by different letters are significatively different, Tukey test, $n=20, p \leq 0.05$ ). In a column, means followed by a common letter are not significantly different at the $5 \%$ level.

\begin{tabular}{cccc}
\hline Treatment & Orchard 1 & Orchard 2 & Orchard 3 \\
Untreated & $8^{\mathrm{c}}$ & $8^{\mathrm{c}}$ & $4^{\mathrm{c}}$ \\
Mancozeb & $44^{\mathrm{b}}$ & $84^{\mathrm{b}}$ & $92^{\mathrm{ab}}$ \\
Azoxystrobin & $96^{\mathrm{a}}$ & $100^{\mathrm{a}}$ & $84^{\mathrm{a}}$ \\
Thiophanate methyl & $100^{\mathrm{a}}$ & $96^{\mathrm{a}}$ \\
\hline
\end{tabular}




\section{Discussion}

Fungicide treatments in 2009, helped preserve between $30 \%$ and $80 \%$ of mangoes in the treated foliage portion and $5 \%$ to $50 \%$ from untreated foliage portions of sprayed mango trees. This level of protection was achieved despite the late application ( $10 \%$ of fruits were infested at application time). These results show a fair curative efficacy of the used fungicides as already reported for azoxystrobin [5]. Systemicity of the 3 fungicides [6] allowed achieving a fair protection of mangoes in the same tree in foliage portions not covered by the application. This property is of great importance in the local conditions of Casamance where rainfall can be very frequent. Indeed, the frequency of rain could be a limitation factor for contact pesticides. The tallness of the mango trees and the large volume of foliage to be covered are additional reasons for the preference of systemic fungicides. The absence of atomizers capable of propelling the spray into the canopy of trees (more than 10 meters high), because of their high cost, is an additional constraint to the use of contact fungicides.

The better results for protection on tree portions physically covered by the fungicides may indicate that the systemic fungicides were not fully absorbed and mobile within the tree.

Fungicide treatments carried out in 2010 showed a better efficacy ( $100 \%$ for thiophanate methyl and $\approx 90 \%$ for azoxystrobin) compared to 2009. Treatment with Mancozeb (contact fungicide) was less effective than thiophanate methyl and azoxystrobin. This could be mainly due to its non systemic effect because the major part of the active substance is probably washed off by frequent rainfall in Ziguinchor.

The better efficacy of the fungicides in 2010 could be related to the early (preventive) treatment, before anthracnose lesions were seen on fruits. The cover spray on the entire foliage with an atomizer helped also achieve this result.

These results are consistent with those obtained in California [7] showing that thiophanate methyl was effective to control anthracnose. Other works in the same line also showed that the methyl thiophanate can efficiently control anthracnose [8] [9]. Azoxystrobin was less effective than methyl thiophanate but more effective than myclobutanyl, a trend already reported in a previous work [10].

\section{Conclusions}

Fungicide treatments of mango trees during fruit development in the field showed to be very efficient to control anthracnose. This applies particularly for thiophanate methyl and azoxystrobin. Mancozeb and myclobutanyl were less effective. The choice of product is therefore a key factor for the control of anthracnose. However, efficacy data from field testing are of great importance to make the right choice.

For effective control of anthracnose, the period of treatment plays an important role. Prophylactic treatments with fungicides starting before the beginning of the rainy season, before mangoes get infected by Colletotrichum gloeosporioides may be for an efficient control.

In this particular agro climatic conditions in Casamance, with abundant rainfall and very large mango trees, contact fungicides are less efficient.

Additional data on efficacy of a large number of fungicides would provide a wide range of efficient products, allowing producers to have a diversity of substances that could be combined wisely to prevent resistance.

\section{References}

[1] Ministère de l'Agriculture (Sénégal). Direction de l'Horticulture (2003). Statistiques Horticoles. DH2, Dakar, 15 p.

[2] Arauz, L.F. (2000) Mango Anthracnose: Economic Impact and Current Options for Integrated Management. Plant Disease, 84, 600-611. http://dx.doi.org/10.1094/PDIS.2000.84.6.600

[3] Agence Nationale pour la Statistique et la Démographie (2008) Situation économique et sociale de la région de Ziguinchor. ANDS, Dakar, 143 p.

[4] Diedhiou, P.M., Mbaye, N., Dramé, A. and Samb, P.I. (2007) Alteration of Post Harvest Diseases of Mango Mangifera indica through Production Practices and Climatic Factors. African Journal of Biotechnology, 6, 1087-1094.

[5] Rebollar-Alviter, A., Madden, L.V. and Ellis, M.A. (2007) Pre- and Post-Infection Activity of Azoxystrobin, Pyraclostrobin, Mefenoxam, and Phosphite against Leather Rot of Strawberry, Caused by Phytophthora cactorum. Plant Disease, 91, 559-564. http://dx.doi.org/10.1094/PDIS-91-5-0559

[6] Edgington, L.V., Khew, K.L. and Barron, G.L. (1997) Fungitoxic Spectrum of Benzimidazoles Coumpounds. Phytopathology, 61, 42-44. http://dx.doi.org/10.1094/Phyto-61-42 
[7] Francis, P., Karla, A. and Martinez, C.R. (2008) Detection and Characterization of Benzimidazole Resistance in California Populations of Colletotrichum in Cereals. Plant Diseases, 92, 239-246. http://dx.doi.org/10.1094/PDIS-92-2-0239

[8] Ebenezar, E.G. and Subramanian, K.S. (1996) Chemical Control of Die-Back of Acid Lime Caused by Colletotrichum gloeosporioides. Indian Journal of Mycology and Plant Pathology, 26, 112.

[9] Singh, D. and Agarwala, R.K. (1987) Differential Reaction of Fungicides to Anthracnose of Citrus (C. gloeosporioides) in Vitro and in Vivo. Indian Journal of Mycology and Plant Pathology, 17, 323-324.

[10] Sundravana, S., Alice, D., Kuttalam, S. and Samiyappan, R. (2007) Efficacy of Azoxystrobin on Colletotrichum gloeosporioides Penz Growth and on Controlling Mango Antracnose. Journal of Agricultural and Biological Science, 2, 10-15. 
Scientific Research Publishing (SCIRP) is one of the largest Open Access journal publishers. It is currently publishing more than 200 open access, online, peer-reviewed journals covering a wide range of academic disciplines. SCIRP serves the worldwide academic communities and contributes to the progress and application of science with its publication.

Other selected journals from SCIRP are listed as below. Submit your manuscript to us via either submit@scirp.org or Online Submission Portal.
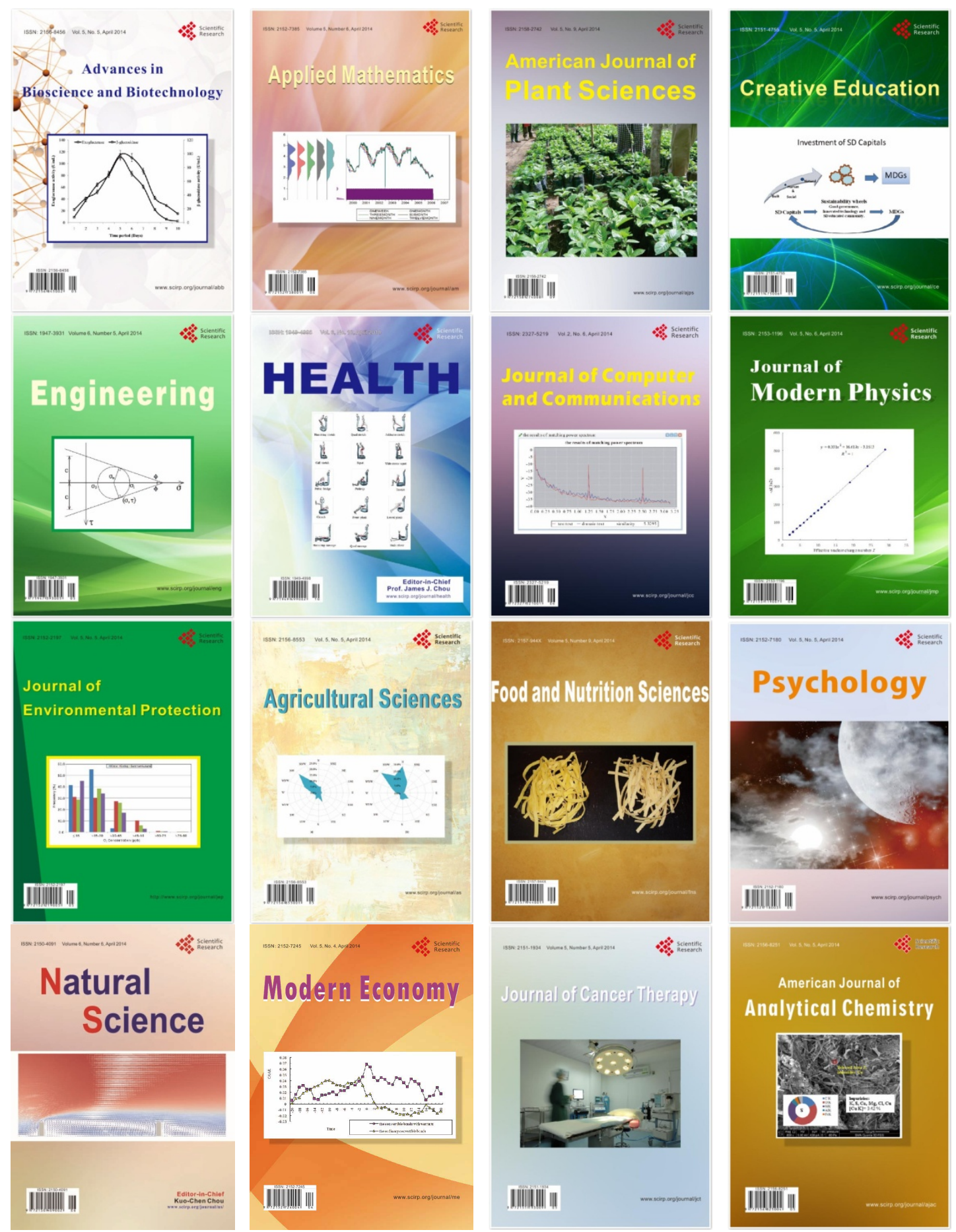